\title{
Waste Management Mind Map: Public Environmental Awareness Project and Creativity in Knowledge and Performance
}

\author{
Fatema K. Al-Asfour ${ }^{1} \&$ Heba A. Al-Helailah ${ }^{2}$ \\ ${ }^{1}$ Department of Environmental Health, College of Health Science, the Public Authority for Applied Education \\ and Training, Kuwait \\ ${ }^{2}$ Department of Environmental Technology Management, College of Life Sciences, Kuwait University, Kuwait \\ Correspondence: Fatema Al-Asfour, Department of Environmental Health, College of Health Science, the Public \\ Authority for Applied Education and Training, Kuwait City, Surra, Zip Code 45405, Kuwait. Tel:_965-9794-9420. \\ E-mail: eng.fatima135@gmail.com
}

Received: February 15, 2018

doi:10.5539/jsd.v11n3p223

\author{
Accepted: April 14, $2018 \quad$ Online Published: May 30, 2018
}

URL: https://doi.org/10.5539/jsd.v11n3p223

\begin{abstract}
A progressive society wants to raise awareness, especially what affects everyday life. This study focuses on simplification waste management by using Mind Map. The cornerstone of this research is the use of mind maps in the field of environmental awareness, increasing environmental awareness of waste negative impact, minimizing its use, and the healthy and environmentally safe alternative. The researcher seeks to link the concepts and goals the 17 goals of sustainable development of United Nations Educational, Scientific and Cultural Organization (UNESCO), with awareness of waste management and modern theories of learning, in order to reach new methodology used in awareness activities. Applied the feasibility and impact of Mind Maps on understanding and simplifying the waste management course for students' community at the Environmental Health department College of Health Science. Buzan's iMindMap 4 software was used to create mind maps for simplifying the project of waste management, the software uses lines, colours, arrows, branches to show connections between the ideas generated. Results of meta-analysis of concept waste management mind maps in student community indicated that concept mapping has positive effects on understanding, assimilation and application, Post-test results showed that experimental community made higher gains in understanding, easy to add ideas, Help you focus on the links and relationships between ideas so you don't just have disconnected facts. Researchers will be based on results in the awareness activity to reach an optimal understanding of the negatives of waste and the responsibility of the community.
\end{abstract}

Keywards: environmental awareness, knowledge mapping, mind maps, survey, sustainable development, waste management

\section{Introduction}

The high rate of population growth, population concentration in urban cities, changing modern lifestyles, and high level of well-being.

Has exacerbated the problem of waste, which adversely affects the health of the environment and thus human health. Forcing officials, researchers, economists and politicians to study the best solutions and modern applications in the field of waste management.

Despite the magnitude of the problem, the world is now using all the available technologies in this field and opening new horizons that contribute to increasing environmental awareness among all members of society. And a concerted effort to provide a safe alternative to the health of the materials consumed by humans every day. Making the most of the waste by recycling it and producing energy.

In addition, there is a need for a complete rethinking of "waste" - to analyses if waste is indeed waste. The aim of research first is to study the effectiveness of the use of Mind Maps in the public awareness of waste management. Second to Training environmentalists on technique to help them understand waste management as an integrated unit.

The most important scientific basis on which sustainable development is based is the building of man, intellect and body. And protecting the environment by protecting the sources of life on earth, water, air and soil. Proper waste 
management is job opportunities for future generations and lost profits.The main and important factor is community awareness of waste in quantity and quantity.

It is an ecological, economic, and social problem for the Kuwait in present-day conditions.

"Education can, and must, contribute to a new vision of sustainable global development. " - (UNESCO, 2015).

Education that promotes economic growth alone may well also lead to an increase in unsustainable consumption patterns. Education is a goal and a means to achieve sustainable development. "Education for Development" is a global program of action that UNESCO seeks to achieve. In order to create a successful awareness, the researcher linked 7 of the 17 sustainable development goals with the better waste management policy for the better life. Through:-

\section{1) Goal 3: Good Health and Well-Being;}

1.1. The successful management of waste contributes to the preservation of the health of the environment and human health.

2) Goal 6: Clean Water and Sanitation;

2.1. Proper societal understanding of waste ensures the safety of water resources.

3) Goal 7: Affordable and Clean Energy;

3.1. Community awareness of the importance of recycling will lead to the preservation of renewable sources of nature (paper recycling and papermaking).

4) Goal 8: Decent Work and Economic Growth;

4.1. Integrated Waste Management is a profit and job opportunity for the future.

5) Goal 9: Industry, Innovation and Infrastructure;

5.1. Waste recycling promotes innovation and industry without the use of raw materials.

6) Goal 12: Responsible Consumption and Production;

6.1. Community understanding of the importance of applying waste minimization from sources and choosing a safe alternative to health.

\section{7) Goal 13: Climate Action;}

\subsection{Successful management of waste will contribute to solving the problem of climate change and global} warming through conservation of natural resources and waste treatment rather than disposal.

A critical component in any waste management program is public awareness, because waste is the result of human activities and every one need to have a proper understanding of waste management issues.

A considerable body of research indicates the effectiveness of using mind maps in facilitating meaningful, the mind maps technology will contribute to edification the community to understand and apply waste management.

Second: Education is such competitive environment to apply of effective problem solving methods, which has led to increased improving the educational and creative level of understanding, protecting, preserving and awareness of community of environmental health field.

Environmental students need to thick, understand, and work in order to realize environmental challenges on the earth with time management.

The researcher, find ways on how to develop a framework for implementing and evaluating such program. Researcher applied mind maps technology. The term Mind Map is a registered trademark of the "Buzan Organization Limited". A Mind Maps gives your brain another way simple, effective, and enjoyable of accessing, processing and expressing the information you take in.

Therefore, the main purposes of this research are:

1) Applying Mind Map as waste awareness project by measuring the impact of Mind Maps on understanding and simplifying the study.

2) Measuring the effectiveness of application of the use of mental mapping technology to explain and study scientific and engineering course, discuss and reduce time necessary to understand and review the scientific courses. 


\section{Material Study}

Research community: Experiment group 116 students (19-23) years' old_Public Authority of Applied Education and Training / Health Science College / Environmental health Department.

Tools: Computer program "iMindMap 4"_Excel analysis program_SPSS _ Survey.

\section{Methodology}

The researcher applied the idea of mental literacy and a thinking technique called "Mind Maps". Survey instrument was designed to evaluate responses and impact of the application of mind maps on understanding, retention and revision of waste management course and awareness. We used SPSS to analyze data.

This study contains two ways to measure the reactions: First: by observation; through their midterms and final examinations. Second: through questionnaires and survey.

Table 1. Questions asked through the survey

\begin{tabular}{cl}
\hline $\mathrm{Q}_{\mathrm{i}}^{*}$ & \multicolumn{1}{c}{ The Survey Questions } \\
\hline $\mathrm{Q}_{1}$ & Do you have difficulty in saving and remembering information? \\
$\mathrm{Q}_{2}$ & Have you ever heard of mental maps and their applications? \\
$\mathrm{Q}_{3}$ & Have you used mental maps before this time? \\
$\mathrm{Q}_{4}$ & How to describe your use of mental maps in a waste management course? \\
$\mathrm{Q}_{5}$ & Best time to use mental maps in review? \\
$\mathrm{Q}_{6}$ & Understanding and study were easier by using mind maps? \\
$\mathrm{Q}_{7}$ & Did the use of mental maps affect your academic level? \\
$\mathrm{Q}_{8}$ & Mind maps help keep and remember information? \\
$\mathrm{Q}_{9}$ & Obstacle in application of mind maps? \\
$\mathrm{Q}_{10}$ & Do you think about using mental maps in the future? \\
${ }^{*} \mathrm{Q}_{\mathrm{i}}=$ Numbering questionnaire questions.
\end{tabular}

The two main way to deliver information were applied in waste management course: traditional and an "iMindMap 4" program as shown in Figure-1 and figure-2. A total number of 116 Public Authority of Applied Education and Training - Health Science College - Environmental Health Department students responded to a questionnaire that was designed for this study. The number of respondents included in this study was considered as a representative sample. Data collection was based on a paper questionnaire. The questionnaire consisted of questions on demographics and personal perspectives about using Mind Map in waste management course were analyzed using the Statistical Package for Social Studies (SPSS). Descriptive analyses were expressed in term of percentages. Pearson correlation coefficients were calculated. The level of significance for these tests was set at $\mathrm{P}<0.05$.

Buzan's iMindMap 4 application is the official Mind Mapping software from the inventor of Mind Mapping, A refreshingly easy, different and practical way to think and work. It has practical applications in your personal life, your professional life, some specifics here are just a few examples of what you could use iMindMap for (remember this list is far from exhaustive and will give you some ideas):-

1) To do lists

2) Planning activities of any kind (holidays, parties, conferences)

3) Collating research

4) Managing projects

5) Developing presentations

6) Organizing the index system for your toenail clipping selection.

However, here are some of the more obvious benefits of Mind Maps created with software like iMindMap: teaching, simplify ideas for community, You can link to other files, folders and webpages, They are easy to save, print and copy, You can share them electronically with other people, You are not limited by the size of a piece of 
paper - you can create maps of any size you want, it is possible allowing you to export your maps to other programs like the more popular word processing and project management software. It's kind of application that makes tips, tricks and techniques for getting the most from Buzan`s iMindMap 4.

Through the work in academic and environmental field. Environmental awareness needs new methods and techniques, because public awareness is a key to successful waste management program. Students at the university face difficulties in summarizing, memorizing, applying and remembering information. This research studies the possibility of mind maps to facilitate the educational process. Waste management - subject category and content: The course covers waste characteristic [type, generation and composition of waste], national and international regulations for waste, waste physical, chemical, and biological properties, integrated waste management, Waste treatment process, the best option of waste management, collection and transport of waste, collection analysis: estimating truck capacity and cost, separation station - processing technique, waste treatment process, resource conservation and recovery [reuse, recycling and recover], incineration, composting, landfill disposal, and finally; identify technologies appropriate to changing environment.

The researchers streamlined and summarized the waste management course using mental maps, which are divided into two main parts.

The mind maps are the outcome of researchers experience gained while dealing with the topics covered both in teaching as well as in practical field. The mind maps are broadly split into two parts.

Part I; first mind map: "Waste Management" deal with the subject of definitions, generation, characterization, properties, and integrated of waste management. The researchers designed maps in the middle the main address and branches, which numbered from 1 to 5 at different colors to be more influential. The sub-branches of each main branch were added as needed. The Section (1) contains the most important definitions that explain the concepts of waste management, the section (2) includes the types of materials contained in the waste, the third section is the characteristics of the waste and is divided into two other branches, which include the first different sources of waste and the second for type of waste, and The fourth section is concerned with the properties of the waste as it deals with the physical, chemical and biological properties of waste, then left some to be used by students for their comments. About the fifth branch, it was divided into sections (A, B, C, \& D). The branch (5-D) was the main address of the second mind map. As shown in Figure 1. 


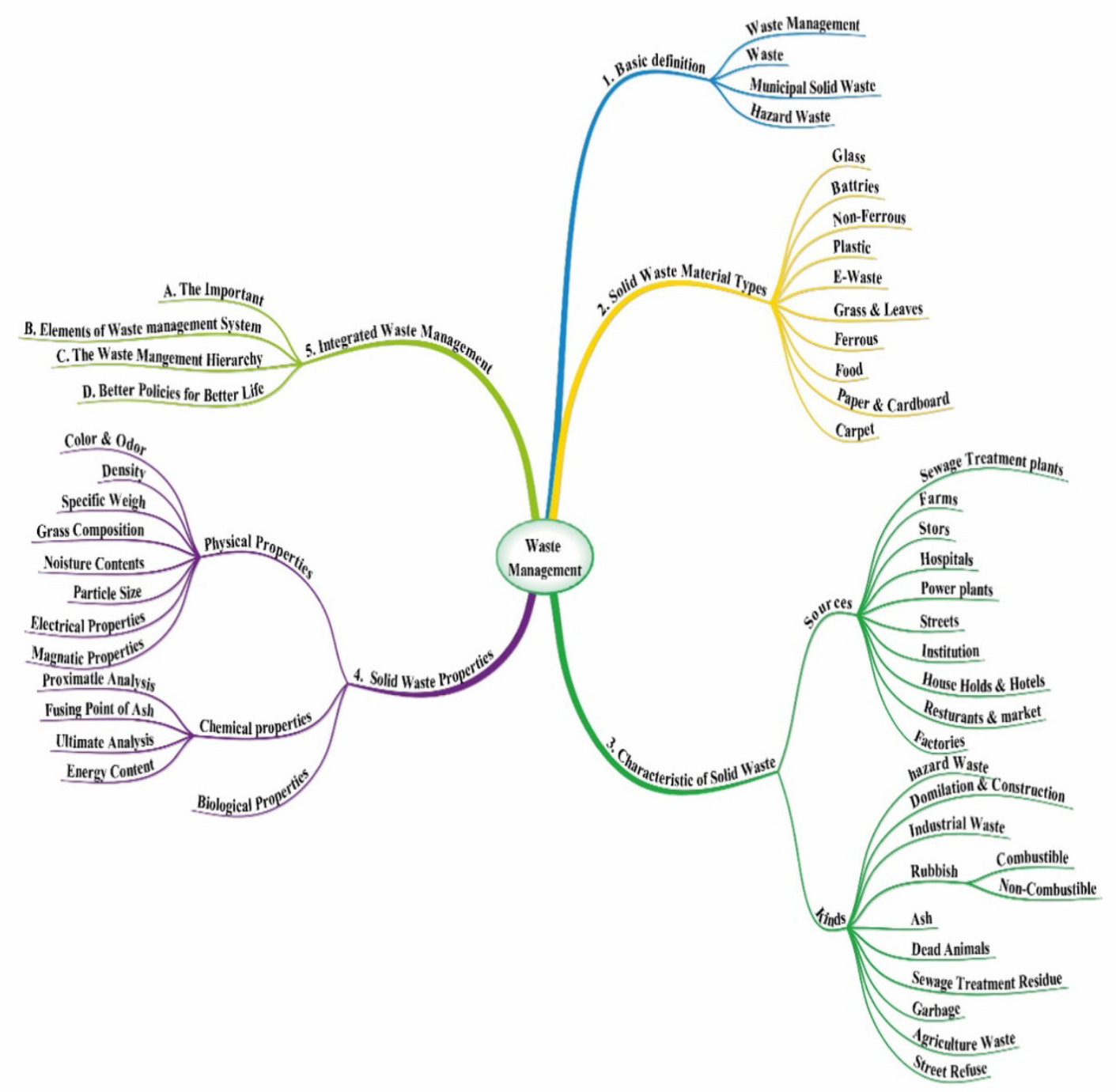

Figure 1. Mind Map Part I: Waste management

Part II; second mind map:" Better Policy for Better Life" This section describes the best ways to deal with waste for better life, human health and its environment according to engineering process and international regulatory development to achieve sustainable development. It has been arranged in five branches according to the reduction of use, receipt, transfer, and priority disposal. As shown in Figure 2. 


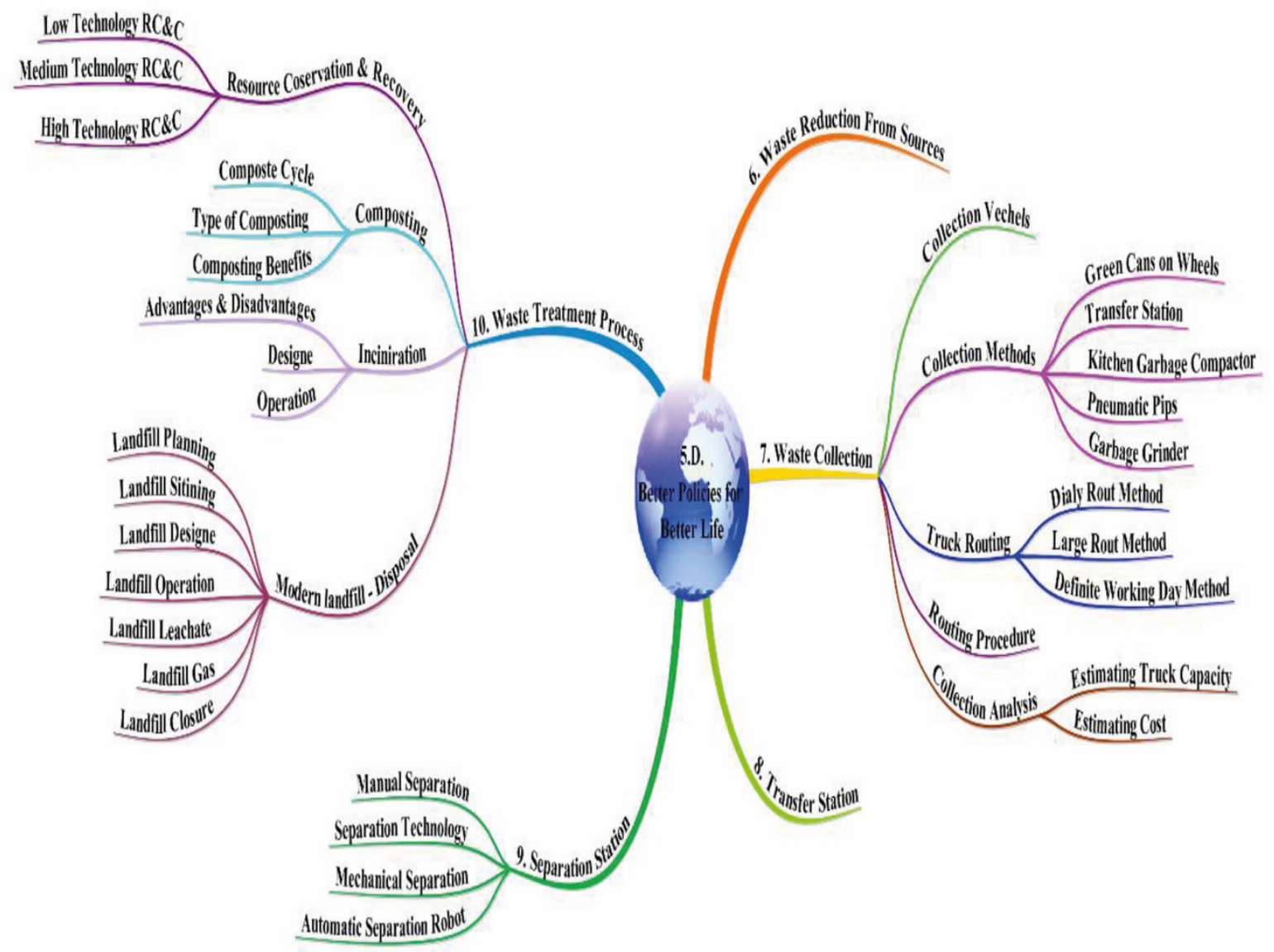

Figure 2. Mind Map Part II: Better Policy for Better Life

\section{Literature Review}

There are several studies that distinguish the waste management and how to sustain them in the society such as, Lazarevic et al. (2010) discussed plastic waste management in the background of a European recycling society and comparing results and suspicions in a life cycle perspective within last 15 years.

Sembiring and Nitivattananon (2010) investigated the sustainable solid waste management near an inclusive society for the integration of the informal sector. The study examines the effectiveness of waste separation and recycling, through informal bodies. In addition to research the advantages and disadvantages of the application of waste management in this way and its effects in the political community and officials in the local municipality. The study shows how raising the level of waste collection and modern applications will negatively affect the increase in unemployment. This is a challenge for officials and decision-makers.

Tukahirwa et al. (2010) discussed civil society participation in urban sanitation and solid waste management in Uganda. One of the main obstacles facing the implementation of successful projects in the management of waste and sewage treatment is the troubled political climate in the country and the financial situation.

Asnani (2006) studied the study indicates that despite the services provided by the municipality in the management of waste, there is an urgent need to apply advanced techniques in this field. The study is likely to cause population growth and population density in urban areas.

Hoornweg and Tata (2012) The study discusses and discusses waste management, which is supervised by the municipality, by addressing the inflation of solid waste and its main causes, the most important of which is the increase of population and urban life. The study builds on a vision that the proportion of waste is increasing with population growth.

Sharholy et al. (2008) the study is concerned with studying the negative outcomes of non-advanced waste management projects and their applications in Indian cities.

Sudhir et al. (1997) studied the planning for sustainable solid waste management in urban India. Presented a 
system dynamics model which captures the dynamic nature of interactions among the various components of the USWM system in a typical metropolitan city.

Shekdar (2009) investigated Sustainability in waste management projects is a requirement for Asian cities. The approaches for SWM should be compatible with the nature of a given society, and, in this regard, Asian countries are no exception. In keeping with global trends, the systems are being oriented to concentrate on sustainability issues; mainly through the incorporation of $3 \mathrm{R}$ (reduce, reuse and recycle) technologies. However, degree and nature of improvements toward sustainability are varying and depend on the economic status of a country. High-income countries like Japan and South Korea can afford to spend more to incorporate 3R technologies.

\section{Result and Discussion}

Quantitative Data and Analytical Results: -

Through the study it was observed that the students feel that their minds have more capacity to make connections and then to store the information's, it also faster creativity, learning easier, make teaching more effective, interest, and improves writing, organization of thoughts, saves time, and improves results. Students response to the questionnaire show that a mind map captures helps us record, memories, connect and output information in a visually expressive way, as shown in table 2 .

Table 2: Analysis of questionnaire results

\begin{tabular}{ccccccccccc}
\hline \multirow{2}{*}{ Answer $^{*}$} & \multicolumn{10}{c}{$\mathrm{Q}^{* *}$} \\
\cline { 2 - 12 } & Q1 & Q2 & Q3 & Q4 & Q5 & Q6 & Q7 & Q8 & Q9 & Q10 \\
\hline \% of Agree & 56.03 & 75 & 23.27 & 67.2 & 79.31 & 34.48 & 99.14 & 75 & 22.4 & 99.14 \\
\% of Sometimes & 33.62 & 0 & 76.72 & 31.9 & 0 & 0 & 0 & 23.3 & 74.1 & 0 \\
\% of Disagree & 10.34 & 25 & 0 & 0.86 & 20.69 & 65.52 & 0.86 & 0.86 & 0.86 & 0.86 \\
\hline
\end{tabular}

$*$ Answer $=$ Average percentage of poll results of survey

${ }^{* *} \mathrm{Q}_{\mathrm{i}}=$ Numbering questionnaire questions.

After comparing the results of final exam - where mind map applied - with midterms - before mind map applied- as shown in figure 3 .

MIDTERM EXAM

घepetition $\quad$ The successful

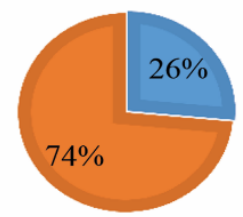

Figure 3. Analysis of results of mid-semester exams

Analysis of results of final semester exam
FINAL EXAM

- Repetition $\quad$ - The successful

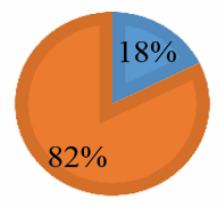

Figure 4. Analysis of results of final semester

The result indicates that the raise of average of student's grades in the final exam [after the explanation and use of mind maps] - as shown above in figure 4- more than the tests of mind terms exam. Notes, that the students' answers were more arranging ideas, systematic answer, explicit and specific.

The repetition rate of students in the first and second exam $26.47 \%$, but in the final exam was $17.65 \%$. Statistical computation using Microsoft excel \& SPSS.

The evidence was collected by questionnaire, and researchers analyze the result of survey, as follows: -

1) $56.03 \%$ of students have difficulty saving and remembering information.

2) $67.2 \%$ of students find mind maps that simplify the course.

3) $79.31 \%$ of students find the best time to use mental maps is to review and study. 
4) $99.14 \%$ of students found that the use of mind maps increased the level of academic and scientific achievement.

5) $74.1 \%$ of students find that difficulty of applying mind maps is the obstacle in their use.

6) $99.14 \%$ of students will continue to use mind maps in the future.

7) From question $3 \& 10$; desire and readiness to use of mind maps in the future $99.1 \%$. On the other hand outputs indicate that $75.9 \%$ have never used mind maps, and $23.3 \%$ have already used mind maps. This is a powerful indicator of the effectiveness and impact of mind maps in understanding, simplifying, facilitating information and tasks.

8) From question $4 \& 6$; the results of the participants that $46.6 \%$ confirm that the use of mind maps facilitates study, understanding and application, through waste management. However, $20.7 \%$ do not support that. This is another indication of the effectiveness of the maps and the importance of their use.

Not: You will find this in Figure 5 of the statistical analysis of the results of the questionnaire for The survey.

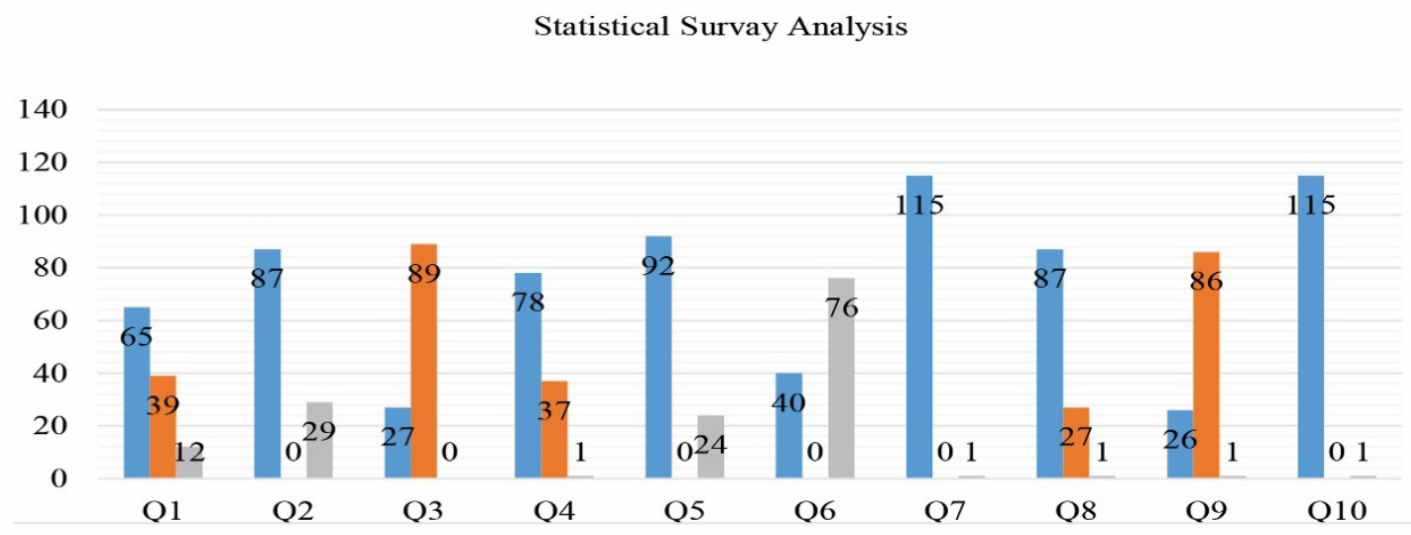

Figure 5. The statistical analysis of the results of the survey

9) As indicated by the results of the statistical analysis:-

9.1. 44.8\% who say have difficulty saving and remembering information and the mind maps help keep and remember information.

9.2. $24.1 \%$ who say sometimes have difficulty saving and remembering information and the mind maps help keep and remember information.

9.3. $6.9 \%$ who say have not difficulty saving and remembering information and the mind maps help keep and remember information.

This study contains two ways to measure the reactions: First: by observation: through their midterms and final examinations. Second: through questionnaires: the questionnaire contains two group of questions:

1) First group of questions measure the understanding factors:-

\subsection{Factor-1: Do you have difficulty in saving and remembering information?}

\subsection{Factor-4: Understanding and study were easier by using mind maps?}

\subsection{Factor-5: Mind maps help keep and remember information?}

2) Second group of questions measure the ability of metal maps usage factors:-

\subsection{Factor-2: Have you used mental maps before this time?}

2.2. Factor-3: How to describe your use of mental maps in a waste management course? 


\subsection{Factor-6: Do you think about using mental maps in the future?}

Results of Chi-square $\left(\chi^{2}\right)$ test for interrelation between understanding factors and the ability to usage of metal maps are shown in table 3 , table 4 and table 5 .

Table 3. Comparison of factor-1 of the first group with all the factors of the second group

\begin{tabular}{cccccc}
\hline & & \multicolumn{3}{c}{ Factor*-1 } & \multirow{2}{*}{ P - value } \\
\cline { 3 - 5 } Factor*-2 & Agree & Sometimes & Disagree & \multirow{2}{*}{0.812} \\
& Agree & $35.30 \%$ & $23.30 \%$ & $6.90 \%$ & \\
& Sometimes & - & - & - & \multirow{2}{*}{0.516} \\
& Disagree & $20.70 \%$ & $10.30 \%$ & $3.40 \%$ & \\
Factor*-3 & Agree & $44.80 \%$ & $24.10 \%$ & $6.90 \%$ & \\
& Sometimes & $11.20 \%$ & $8.60 \%$ & $3.40 \%$ & 0.369 \\
& Disagree & $0 \%$ & $0.90 \%$ & $0 \%$ & \\
\hline \multirow{3}{*}{ Factor*-6 } & Agree & $56 \%$ & $33.60 \%$ & $10.30 \%$ & \\
& Sometimes & - & - & - & \\
& Disagree & $0 \%$ & $0.90 \%$ & $0 \%$ & \\
\hline
\end{tabular}

*The definition of each factor in the above first group and second group

Table 4. Comparison of factor-4 of the first group with all the factors of the second group

\begin{tabular}{|c|c|c|c|c|}
\hline & & \multicolumn{2}{|c|}{ Factor*-4 } & \multirow{2}{*}{$P$ - value } \\
\hline & & Yes & No & \\
\hline \multirow{3}{*}{ Factor*-2 } & Agree & $14.70 \%$ & $50.90 \%$ & \multirow{3}{*}{0.75} \\
\hline & Sometimes & - & - & \\
\hline & Disagree & $8.60 \%$ & $25.90 \%$ & \\
\hline \multirow{3}{*}{ Factor*-3 } & Agree & $18.10 \%$ & $57.80 \%$ & \multirow{3}{*}{0.845} \\
\hline & Sometimes & $5.20 \%$ & $18.10 \%$ & \\
\hline & Disagree & $0 \%$ & $0.90 \%$ & \\
\hline \multirow{3}{*}{ Factor*-6 } & Agree & $23.30 \%$ & $75.90 \%$ & \multirow{3}{*}{0.58} \\
\hline & Sometimes & - & - & \\
\hline & Disagree & $0 \%$ & $0.90 \%$ & \\
\hline
\end{tabular}

*The definition of each factor in the above first group and second group 
Table 5. Comparison of factor-5 of the first group with all the factors of the second group

\begin{tabular}{cccccc}
\hline & & \multicolumn{3}{c}{ Factor*-5 } & \multirow{2}{*}{ P - value } \\
\cline { 3 - 5 } & & Excellent & Good & Acceptable & \\
Factor*-2 & Agree & $46.60 \%$ & $18.10 \%$ & $0.90 \%$ & 0.323 \\
& Sometimes & - & - & - & \\
& Disagree & $20.70 \%$ & $13.80 \%$ & $0 \%$ & $<0.000$ \\
\multirow{3}{*}{ Factor*-3 } & Agree & $64.70 \%$ & $11.20 \%$ & $0 \%$ & \\
& Sometimes & $2.60 \%$ & $20.70 \%$ & $0 \%$ & $<0.000$ \\
& Disagree & $0 \%$ & $0 \%$ & $0.90 \%$ & \\
\hline \multirow{2}{*}{ Factor*-6 } & Agree & $67.20 \%$ & $31.90 \%$ & $0 \%$ & \\
& Sometimes & - & - & - & \\
& Disagree & $0 \%$ & $0 \%$ & $0.90 \%$ & \\
\hline
\end{tabular}

*The definition of each factor in the above first group and second group.

The results revealed a significant effect of understanding factors [2\&3] and usage factors $[5](p<0.000)$.

\section{Conclusion and Recommendations}

This study suggests some recommendations as it mentioned below:

First; the use of mind mapping approach to help students think smarter, understand whole brain thinking, feed the mind with information in order, gradually and clearly. There is no memory limit with mind maps.

Second; applications that use of mind maps in community awareness help to understand and manage the meaning of waste. That can face the difficulty of waste management policy.

Third; after the researchers collected the evidence through the questionnaire and analyzed the results and the final and final tests of the students. To demonstrate the feasibility and impact of mind maps in waste management. The researchers concluded that the application of mental maps to bridge the gap and overcome the difficulties facing the awareness of the community environment in the field of waste treatment and negative impact of waste, reduce their use, also choose a safe alternative to the environment and human health.

Finally; the researcher will draw on the results of this research for the next stage, environmental awareness of the negativity of waste and the optimal utilization of the environment conservation.

\section{References}

Ali, G. B. (2013). The effect of mind mapping applications on upper primary students' success and inquiry-learning skills in science and environment education. International research in Geographical and $\begin{array}{lllll}\text { Environmental } & \text { Education. } & \text { Pp. } & \text { 337-352. } & \text { Retrieved }\end{array}$ https://www.tandfonline.com/doi/abs/10.1080/10382046.2013.826543

Asnani, P. U. (2006). Solid waste management. India infrastructure report, 570. Retrieved from http://www.mumbaidp24seven.in/reference/Solid_Waste.pdf

Buzan, T. (2013). Modern Mind Mapping for Smarter Thinking. Cork: BookBaby. Retrieved from https://books.google.com.kw/books?hl=en\&lr=\&id=_itbDQAAQBAJ\&oi=fnd\&pg=PT2\&dq=+3.\%09+Buz an, + T. $+(2013) .+$ Modern+Mind+Mapping + for + Smarter+Thinking. + Cork: + BookBaby. $+\& o t s=x 1 A H k 1 g K C$ V\&sig $=\lg 4 \mathrm{xv}$ syo-JJjIQbThm_ebHF8vTs\&redir_esc $=\mathrm{y} \# \mathrm{v}=$ onepage \&q\&f$=$ false

Chawla, L., \& Handers, D. (2007). Cushing. Education for Strategic Environmental Behaviour. Journal of Environmental Education Research, 437-452. http://dx.doi.org/10.1080/13504620701581539

Fränzle, S., Markert, B., \& Wünschmann, S. (2012). Introduction to environmental engineering. Weinheim: Wiley-VCH. Retrieved from https://onlinelibrary.wiley.com/doi/10.1002/9783527659487.ch4

Hoornweg, D., \& Bhada-Tata, P. (2012). What a waste: a global review of solid waste management. Retrieved from https://openknowledge.worldbank.org/handle/10986/17388

Lazarevic, D., Aoustin, E., Buclet, N., \& Brandt, N. (2010). Plastic waste management in the context of a European recycling society: comparing results and uncertainties in a life cycle perspective. Resources, 
Conservation and Recycling, 55(2), 246-259. https://doi.org/10.1016/j.resconrec.2010.09.014

Perron, G. M., Cote, R. P., \& Duffy, J. F. (2006). Improving environmental awareness Training in business. Journal of clear production, 551-562. https://doi.org/10.1016/j.jclepro.2005.07.006

Pichtel, J. (2005). Waste Management Practices Municipal, Hazardous.

Sembiring, E., \& Nitivattananon, V. (2010). Sustainable solid waste management toward an inclusive society: Integration of the informal sector. Resources, Conservation and Recycling, 54(11), 802-809. Retrieved from http://citeseerx.ist.psu.edu/viewdoc/download?doi=10.1.1.661.2270\&rep=rep1\&type=pdf

Sharholy, M., Ahmad, K., Mahmood, G., \& Trivedi, R. C. (2008). Municipal solid waste management in Indian cities-A review. Waste management, 28(2), 459-467. Retrieved from https://www.researchgate.net/publication/6394075_Municipal_solid_waste_management_in_Indian_cities_ -_A_review

Shekdar, A. V. (2009). Sustainable solid waste management: an integrated approach for Asian countries. Waste management, 29(4), 1438-1448. https://doi.org/10.1016/j.wasman.2008.08.025

Sudhir, V., Srinivasan, G., \& Muraleedharan, V. R. (1997). Planning for sustainable solid waste management in $\begin{array}{llllll}\text { urban India. } & \text { System } & \text { 223-246. }\end{array}$ https://doi.org/10.1002/(SICI)1099-1727(199723)13:3\%3C223::AID-SDR127\%3E3.0.CO;2-Q

Tukahirwa, J. T., Mol, A. P., \& Oosterveer, P. (2010). Civil society participation in urban sanitation and solid waste management in Uganda. Local Environment, 15(1), 1-14. https://doi.org/10.1080/13549830903406032

United Nations Educational, Scientific and Cultural Organization (UNESCO) Source: http://unesdoc.unesco.org/images/0024/002474/247444e.pdf\#page36; http://www.unesco.org/open-access/terms-use-ccbysa-en

Wong, K.-K. (2010). Environmental awareness, governance and public participation: Public perception: perspectives. International Journal of Environmental Studies, 169-181. Retrieved from http://www.tandfonline.com/doi/abs/10.1080/00207231003683424

Note: Tony Buzan is the inventor of Mind Maps the most powerful "thinking tool "of our times-, [Anthony peter - Tony Buzan / Educational Consultant].

\section{Copyrights}

Copyright for this article is retained by the author(s), with first publication rights granted to the journal.

This is an open-access article distributed under the terms and conditions of the Creative Commons Attribution license (http://creativecommons.org/licenses/by/4.0/). 